\title{
Presenting a framework for knowledge management within a web-enabled Living Lab
}

\author{
Authors: \\ Lizette de Jager ${ }^{1}$ \\ Albertus A.K. Buitendag \\ Jacobus S. van der Walt ${ }^{1}$

\section{Affiliations:} \\ ${ }^{1}$ Department of Computer \\ Science, Tshwane University \\ of Technology, South Africa \\ Correspondence to: \\ Lizette de Jager \\ Email: \\ dejagerL@tut.ac.za \\ Postal address: \\ Private Bag X680, Pretoria \\ 0001, South Africa \\ Dates: \\ Received: 29 Oct. 2011 \\ Accepted: 05 Mar. 2012 \\ Published: 10 May 2012 \\ How to cite this article: \\ De Jager, L., Buitendag, \\ A.A.K. \& Van der Walt, \\ J.S., 2012, 'Presenting a \\ framework for knowledge \\ management within a \\ web-enabled Living Lab', \\ SA Journal of Information \\ Management 14(1), Art. \\ \#506, 13 pages. http:// \\ dx.doi.org/10.4102/sajim. \\ v14i1.506
}

Background: The background to this study showed that many communities, countries and continents are only now realising the importance of discovering innovative collaborative knowledge. Knowledge management (KM) enables organisations to retain tacit knowledge. It has many advantages, like competitiveness, retaining workers' knowledge as corporate assets and assigning value to it. The value of knowledge can never depreciate. It can only grow and become more and more valuable because new knowledge is added continuously to existing knowledge.

Objective: The objective of this study was to present a framework for KM processes and using social media tools in a Living Lab (LL) environment.

Methods: In order to find a way to help organisations to retain tacit knowledge, the researchers conducted in-depth research. They used case studies and Grounded Theory (GT) to explore KM, social media tools and technologies as well as the LL environment. They emailed an online questionnaire and followed it up telephonically. The study targeted academic, support and administrative staff in higher education institutions nationwide to establish their level of KM knowledge, understanding of concepts and levels of application.

Results: The researchers concluded that the participants did not know the term KM and therefore were not using KM. They only used information hubs, or general university systems, like Integrated Technology Software (ITS), to capture and store information. The researchers suggested including social media and managing them as tools to help CoPs to meet their knowledge requirements. Therefore, the researchers presented a framework that uses semantic technologies and the social media to address the problem.

Conclusion: The success of the LL approach in developing new web-enabled LLs allows organisations to amalgamate various networks. The social media help organisations to gather, classify and verify knowledge.

\section{Introduction}

This research is part of a study into the knowledge management practices of higher education institutions and how these institutions can improve their practices by applying various web technologies, like social media tools and the semantic web, in a Living Lab (LL) environment.

\section{Background to the study}

Recent research papers have pointed out the value of LLs as environments for collaborative innovation and discovering knowledge (Herselman, Marais \& Pitse-Boshomane 2010; Herselman \& Cunningham 2011). As part of ongoing research into agricultural knowledge-driven Communities of Practice (CoPs) in the Southern African context, Van der Walt et al. (2009:421436) and Buitendag and Van der Walt (2009) presented a LL framework that uses web-based technologies as its basis. The LL framework (see Figure 1) uses an agricultural CoP as its basis. However, the same generic knowledge management practices apply in similar contexts and environments, like higher educational, medical and financial environments. Therefore, the researchers present the framework generically.

One of the main objectives of a LL is to use knowledge for further innovation. Knowledge by itself is useless unless one applies it in context. The general objective of a LL is to be a real life collaborative development platform.

\section{Methodology}

The methodology the researchers used in the study was a questionnaire and follow-up telephone calls to investigate the levels of understanding of knowledge management (KM) in higher education institutions nationwide. 
In order to find a way for organisations to retain tacit knowledge, the researchers conducted in-depth research. They used case studies and Grounded Theory (GT) on KM practices and the use of social media tools and technologies in a LL environment.

\section{Findings}

The findings were similar across the board. Either the users did not know the term KM, or worked only with information hubs that used general university systems like the Integrated Technology Software (ITS) to store and capture information, leaving the general users of the system (often individuals) to apply decision making processes with little or no support.

The framework in Figure 1 highlights various research methodologies one could use as part of the knowledge discovery process that leads to innovative solutions and services. The knowledge discovery process, and other collaborative knowledge activities, could generate vast quantities of knowledge within the internal and external domains and make unique KM strategies necessary.

According to Van der Walt et al. (2009), the framework incorporates various 'factories' for accomplishing different tasks and objectives. They include:

- a social networking factory for profiling and registering community members

- a tools or product factory for creating tools and methodologies for the LL

- a service factory for establishing all the services the community needs, which may include physical and nonphysical services like web services

- a knowledge factory that creates a dynamic set of knowledge objects that uses a Question and Answer Extrapolation Tool (QAET).

The QAET uses questions to create reusable knowledge objects. The primary purpose of the QAET is to manage user requests and to create knowledge objects that users store in the Knowledge Object Repository (KOR).

\section{Essential elements of good knowledge management Knowledge objects}

Knowledge objects (KOs) are any artefacts that knowledge seekers could use to learn, or expand their current knowledge, about a topic. Merrill (2000) defines knowledge objects as sets of appropriate components of knowledge that users require for particular needs. The components of knowledge objects include various entities and properties of the entities as well as the various activities that one could associate with the processes of the entities to describe the knowledge they represent.

KOs can have a variety of formats, ranging from digital media to WEB 2.0 mashed objects. A Knowledge Object Repository
(KOR) stores and manages used KOs. A KOR is a semantic web cataloguing and tagging system. The researchers believe that introducing semantic tagging to applicable documents will help to overcome this problem. Tagging ontologies and techniques tag $\mathrm{KO}$ objects semantically. They store and manage the subsequent metadata as part of the semantic knowledge bases and KORs. Organisations, by themselves, cannot use corporate KM fully without using the correct tools to contribute, collaborate and integrate. The Internet provides social media tools for optimal KM functionality. Organisations should manage their knowledge assets so that they can achieve their objectives. This is the first and most important rule when organisations treat knowledge as assets.

Dieng (2002:14-17) emphasised that 'organizational memory aims to deliver the right knowledge to the right person at the right time in the right format to enable the right action'. To apply this concept, organisations must use the correct tools. The Internet provides all the necessary tools and using it makes such an operational platform possible. The Internet allows organisations to integrate knowledge and creates working systems within the cloud. Nabil (2010) defines cloud computing as 'clusters of distributed computers (largely vast data centres and server farms) which provide on-demand resources and services over a networked medium (usually the internet)'.

Doyle (2012) defines social media by stating that:

social media includes the various online technology tools that enable people to communicate easily via the internet to share information and resources. Social media can include text, audio, video, images, podcasts, and other multimedia communications. (n.p)

Social networks are social media sites through which people connect to businesses or people with similar interests.

\section{The intranet, Internet and Living Labs}

An intranet can use internal corporate memory whereas external memory relies on extranets that connect companies and their selected partners. These partners can include customers, suppliers and subcontractors. A number of employees in organisations use the Internet to create and reuse corporate memories. Organisations can create corporate memories, allow them to evolve and then distribute or centralise them. Distributed corporate memories support cooperation and knowledge sharing between numerous people in organisations even if they are geographically dispersed.

Qualman (2010), from Socialnomics, found that over 50\% of the world's population was under the age of 30 in 2009. Therefore, Qualman predicted that the social media were increasing because of the growth and addition of younger generations of users. In the United States of America (USA), $75 \%$ of the current generation uses social media. This figure used a 2010 Pew Research Center study on the millennial generation (Kern 2010) as its basis. Students make up a 


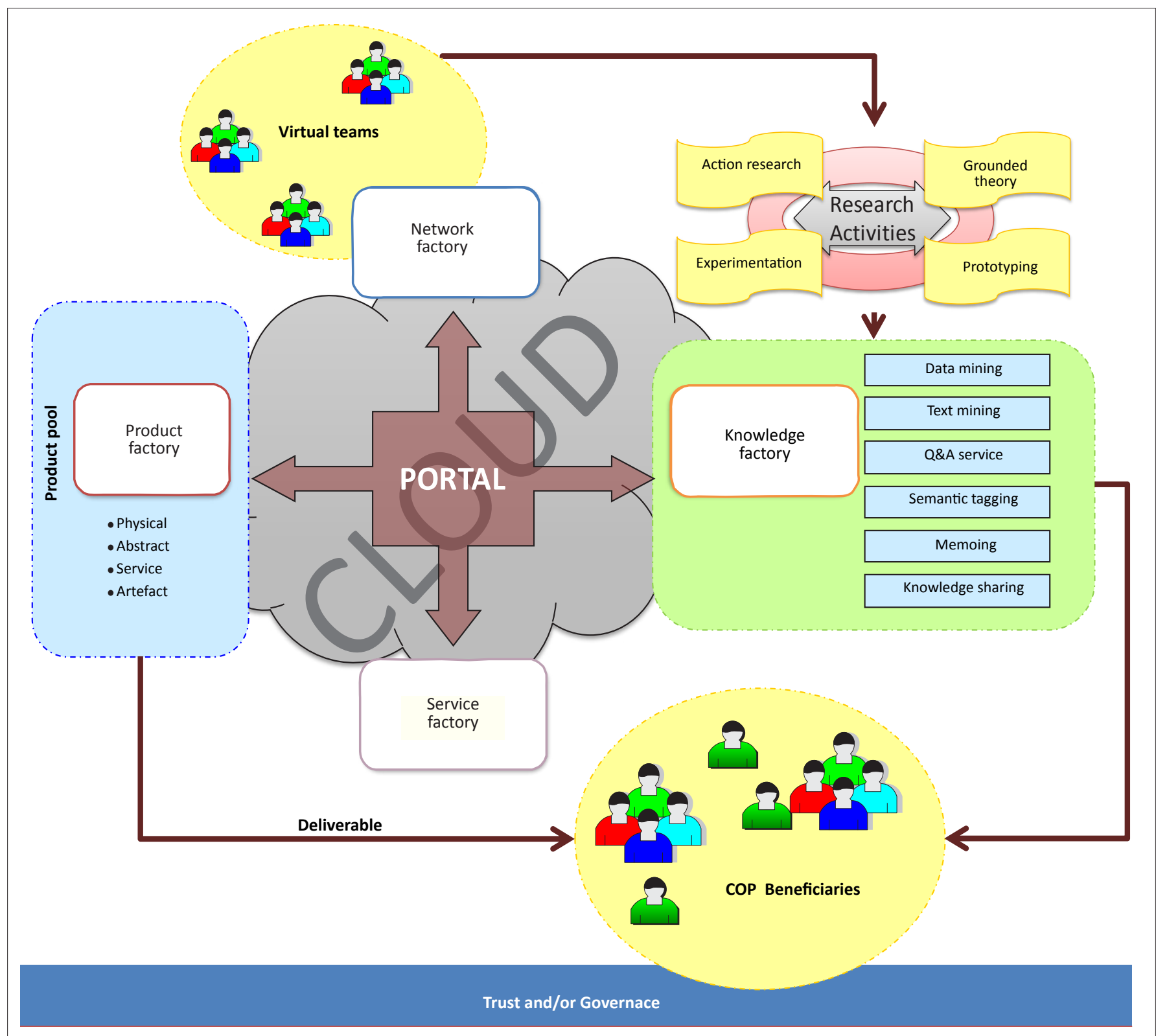

FIGURE 1: Web-enabled Living Lab Framework.

significant proportion of this population. Therefore, the social media is the perfect platform for higher education institutions to roll out KM.

The researchers believe that the social media allow LLs to work. Therefore, integration, collaboration and full participation can occur. LLs for KM allow end users to share and bank knowledge. LLs allow end users to see the bigger picture and provide insight into strategic and behavioural KM efforts. The KM drivers slot in perfectly with social media platforms and allow seamless operation in a LL.

\section{Living Labs, thinking processes and knowledge management labs}

The LL is just a tool organisations use within a cloud. However, they make integration, collaboration and optimisation possible. Pallot (2006) describes a Living Lab as an 'innovation platform' that engages all stakeholders, like end users, researchers, industrialists and policy makers at an earlier stage of the innovation process.

In the knowledge economy, knowledge became the most valuable resource for maintaining competitiveness and advantage for people or organisations (Mukhlason, Mahmood, Arshad \& Abidin 2009:335-339). The value of $\mathrm{KM}$ systems is the way organisations acquire knowledge and apply it after they have captured it. LLs also help organisations to transfer knowledge to various role players or groups.

The social media emphasise the principle of social networking (Wahlroos 2010:7-14). The researchers believe that the Web is the platform for the most creative minds in the world, where the concepts of open innovation and co-creation emerge. Bartl, Jawecki and Wiegandt (2010) explained that open innovation 
refers to opening the innovation process to improve the users' and other stakeholders' knowledge, creativity and skills. The idea of open innovation and co-creation are core activities and processes of a LL environment.

A LL turns environmental knowledge into assets and gives inherent value to the knowledge that organisations generate. From this perspective, knowledge, as an asset, also does not depreciate. Instead, it increases in value over the years because organisations can only build onto their existing assets. Knowledge cannot become outdated but organisations can improve it by adding newer knowledge. Generating knowledge and artefacts are core activities in a LL to stimulate innovation, amongst others, because it is the main reason that LLs exist. Without knowledge, there is no business and organisations will be unable to generate solutions. LL stakeholders learn to apply knowledge themselves. KM, generation and dissemination are the core of LL activities, as cooking is core to restaurants. Without food, there will be no restaurants. Simply put, without knowledge and sound KM, there will be no innovation and no LLs. Applying knowledge means turning knowledge into action. No knowledge becomes dormant, but organisations share it so that others can capture the newer knowledge on the shared aspect. Organisations constantly reintegrate and classify earlier KOs as parts of newer solutions. In turn, they speed up the process of acquiring knowledge.

KM involves connecting people with people and people with information. Technology can speed up strategic decision-making by making knowledge available through databases, intranets, virtual video conferencing, knowledge repositories and collaborative tools for sharing knowledge (Fotache 2002). Newman and Conrad (1999) stated that KM offers a framework for balancing the numerous approaches and technologies that add value and integrating them into seamless wholes. The primary focus of $\mathrm{KM}$ is to use information technology and tools, business processes, best practices and culture to develop and share knowledge in organisations as well as to connect those who hold the knowledge with those who need it (Anantatmula 2005:50 67). According to Zhao, Gütl and Chang (2008), the challenge of $\mathrm{KM}$ is to make the right knowledge available to the right people at the right time. KM connects people with people and people with information.

\section{Thinking processes as parts of a Living Labs environment}

The main objective of any community-orientated LL is to create prosperous communities. Research papers have identified many critical success factors for prosperous communities (cf. Lepik \& Varblane 2010; Eskelinen 2010). The ones they mention most relate to trust, involving members in the innovation process, access to adequate knowledge about the problem environment, state of the art information communication technology (ICT) tools and methodologies as well as good governance. The purpose of a LL is to support core research capabilities and shared understanding in order to learn and understand the thinking processes (Van der Walt \& Thompson 2009).

Thinking is a process of working things out, knowing why and how things work or do not work. A LL is a thinking and rethinking support environment, connected to generic decision-making (intelligence, design, choice and implementation) and action research (sense, learn and act) processes. Simply put, a LL framework that uses thinking as its basis can function as a springboard for prosperous communities to build their entrepreneurial capacities and achieve sustainable continuous improvement (Aronson n.d.).

According to Aronson (n.d.), the LL approach uses systems thinking as its basis. This author continues to identify and describe a number of thinking paradigms. Amongst them are that systems thinking ensures collaborative, innovative, explorative, strategic and process thinking.

Multidisciplinary and collective intelligence thinking supports collaborative thinking. Performance, value chain and factory thinking support innovative thinking. Critical, Grounded Theory, action research and experimental research thinking support explorative thinking. Workflow, architectural, real time, risk, effectiveness, maturity and intelligent services thinking support process thinking.

Systems-thinking.org (2011) explains that systems thinking is a mindset for understanding how things work. It is a way of going beyond events, looking for patterns of behaviour or seeking underlying systemic interrelationships that are responsible for behavioural patterns and events. Systems thinking embodies a worldview. On the other hand, innovative thinking links to creative thinking and to solving problems. It generates new things or finds new ways to solve them. Explorative thinking stimulates innovation by finding patterns in data, events, design processes, research processes and decision-making. These patterns transform into knowledge and best practices in order to improve human cognition and derive fundamental insights into complex problems and systems. Analytical and critical thinking research processes support the process of discovering (Van der Walt \&Thompson 2009).

Critical thinking is the means and ends of learning. Critical thinkers should:

- remain open to new ideas and think like scientists

- be sceptical about ways of doing things

- use and create their own information and reject information that is irrelevant and faulty

- state their own arguments

- come to their own conclusions

- listen to other people and tolerate their ways of thinking (Van der Walt \&Thompson 2009). 
Strategic thinking is a way of thinking about changes and preparing for them. It is a process of helping organisations to confront changes, analyse their effects and look for new opportunities (Thompson, Strickland \& Gamble 2007).

Simply put, performance thinking helps organisations to achieve their strategic goals. Performance thinking is the process of assessing progress toward achieving predetermined goals. Performance management builds on that process and adds the relevant communication and action to the progress organisations make in achieving their predetermined goals (Wikipedia 2008).

The main purpose of performance thinking is to link performance objectives with organisational strategies to increase profit. A performance problem is any gap between desired and actual results. Performance improvement is any effort targeted at closing the gap between actual results and desired results (Van der Walt et al. 2009).

Process thinking focuses on identifying, understanding, designing and managing processes. Activities and related activities from workflows lead to the completion of work - objective integrated systems manage it. Workflow, architectural, real time, risk, effectiveness, maturity and intelligent services thinking support process thinking (Van der Walt et al. 2009).

It is clear that, in a LL environment, one needs to control the various thinking processes and to manage the subsequent processes in order to ensure that the various thinking processes result in manageable deliverables in the form of $\mathrm{KO}$ as well as other knowledge artefacts and solutions.

\section{The social media and knowledge management}

Organisations are becoming extremely interested in the benefits of applying Web 2.0 technologies to their work practices. They include social media tools like blogs, wikis, Really Simple Syndication (RSS) feeds, sharing content, tagging and social networking. Online or Web 2.0 communities are people who share a common purpose and organisations use them to improve their business (Leask 2009). Facebook, MySpace and Twitter are 'the big three' in social networking. The researchers believe that organisations should follow a targeted approach when using social media websites based on demographics.

These social spaces play significant roles as sources and enablers of the network and knowledge factories (see Figures 1 and 2). Tools, like blogging tools, social media tools and content sharing tools (such as Flickr and YouTube) are freely available and the only expenses they incur are Internet up-time and website maintenance. The tools have worldwide recognition and are the most popular Web 2.0 platforms because they are easy to use and support knowledge distribution between organisations and various
CoP members, both internally and externally. Community social websites intend to design a common platform for an intended purpose. It is also possible to customise websites in order to share and capture knowledge as well as to communicate with various audiences.

Organisations want to benefit by engaging with a large group of people who provide knowledge. Organisations can then use this knowledge to assist them with their strategies and to improve their products and services. The success of the social media depends on meeting the right online users in the right settings with the right messages. KM, according to Reichental, Gamliela and Ayalb (2007:1-22) is the identification, retention, effective use and retirement of institutional insight. However, it has been an elusive goal for most large organisations. The emergence and effect of the social media on organisations forces them to rethink KM and creates completely new challenges for them. Today, one can categorise some of the core issues with existing KM approaches as behavioural and technical in nature. In order for a KM system to have value, employees must contribute knowledge regularly. The researchers believe that a KM system that uses LL tools will achieve the best results. In a LL setting, organisations achieve optimisation by transferring knowledge between experts and knowledge seekers and vice versa. LLs improve collaboration between many entities. This ensures that they capture up to date knowledge and more thinking can go into a subject. Involving more experts leads to specialist knowledge in the KM system.

A KM system, which uses LL tools, is especially important for CoPs because many experts reside outside the geographical boundaries of the LL. Collaboration links with knowledge transfer and technologies. From the point of view of LL tools, large groups, internal and external to CoPs, can use many technologies in order to share and capture knowledge that is wider than the CoPs themselves are. In a LL, organisations capture data and information and then convert them into knowledge. The collaborative environment supports problem solving by applying the knowledge in the knowledge bank (Van der Walt et al. 2009).

The researchers constructed Figure 2. It is an adaptation from Melakoski (2007) and Roux, Buitendag and Van der Walt (2008) and shows some social media (Web 2.0) tools that one could use as part of the LL environment. It also highlights their strengths, weaknesses and possible relationships with generating knowledge.

The researchers do not suggest incorporating all possible social media tools in a LL environment. However, the focus of the LL should determine which tools are best suited for its purpose. The number of social tools it includes will have an effect on the KM strategies and approaches it will follow.

The researchers support the notions of Reichental et al. (2007) when they stated that:

it's likely that social-media-driven KM will require much less of the "management" component. Historically we've spent far too 


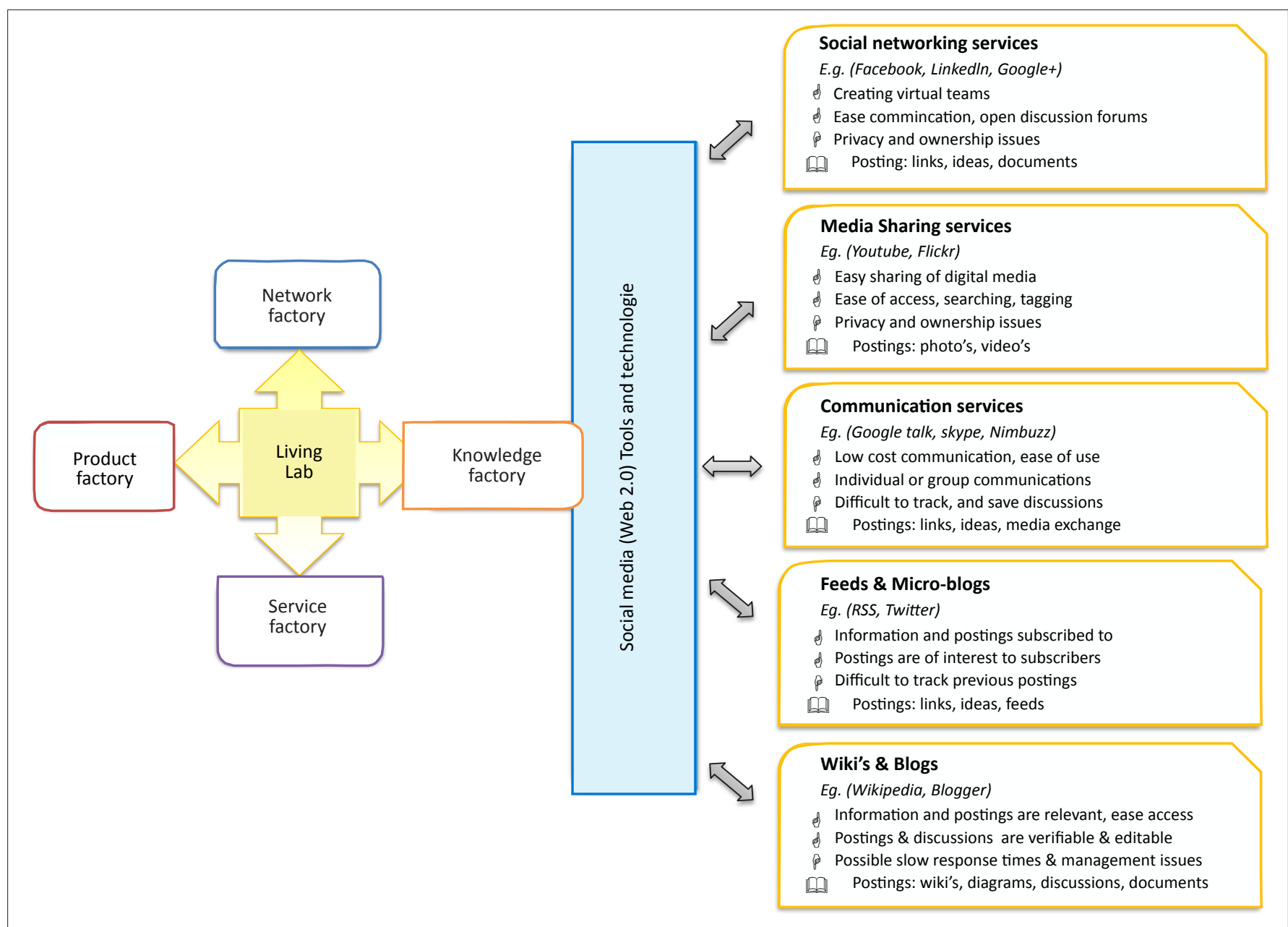

FIGURE 2: Examples of social media (Web 2.0) tools and technologies as part of a Living Lab.

much time cleaning up the data, validating, and categorizing it. In the future, more time will be spent analyzing newly created knowledge through social interactions. Smart analysis can result in new insight, and that has powerful value for organizations. (n.p.)

Some reasons why one should use social media are that one can use them for:

- research

- learning from others

- community building

- sharing expertise

- collaborating in real time.

The Digital Marketing Agency (2010) suggested that connected groups could learn from each other continuously. New ways of managing knowledge between projects and of collecting knowledge from employees who leave companies will reduce the loss of knowledge (Lietsala 2008; Otala 2008).

\section{Grounded Theory and discovering knowledge}

In collaborative organisational and research environments, the GT process could apply in virtual teams. Therefore, it has an effect on the validity of the knowledge because groups of experts and entities in the networked domain could validate it. This process promotes the concept of 'e-collaboration'. Jones and Burger (2009) describe e-collaboration as a new approach to forming and maintaining cooperative enterprises that involve introducing electronic communication tools to facilitate collaboration.

The GT research methodology is one of the primary research activities in the LL domain for discovering knowledge. The GT method gives guidelines for collecting data, analysis and building inductive theory. Researchers collect data and conduct analyses in successive steps (Charmaz 2000). Interpreting the data they collect in one step helps them to focus on collecting the data in the next one. The researchers compared the data and found them to be consistent and parallel. They presented these findings quantitatively as percentage measurements and representations. Davidson (2002) defines and motivates the use of GT by explaining that:

GT is described as a research method in which the theory is developed from the data, instead of the other way around. In doing so makes it an inductive approach, meaning that it moves from the specific to the more general. The study method is fundamentally based on three elements: concepts, categories and propositions, initially called 'hypotheses'. Concepts are the key elements of analysis since the theory is developed from the data conceptualization instead of the actual data. (n.p.) 
Muller (2010), at IBM Research, motivates using GT by stating that:

The GT process is good for explorative research, which lead to the disciplined development of new and innovative ideas, and in developing a theory and structure in areas where there is no a prior guidance, whilst working with both qualitative and quantitative data. (n.p.)

\section{Knowledge interchange and management processes}

The network and knowledge factories are parts of the framework. They provide tools for communicating and disseminating information, called knowledge interchange (KI). The KM researchers, Groff and Jones (2003) and Malhotra (2000:5-16), identified the information technology (IT) capabilities that contribute positively to absorptive KM in organisations:

- knowledge acquisition capability, which is the IT ability to identify, obtain and maintain useful knowledge from several sources

- knowledge distribution capability: IT can distribute knowledge to knowledge consumers

- knowledge identification capability, which is the IT function of retrieving stored knowledge in knowledge repositories and of identifying the sources of expertise effectively

- knowledge upgrade capability: IT can upgrade knowledge effectively and discard irrelevant knowledge.

KI activities and processes correlate closely with KM processes and knowledge sharing (Hall \& Paradice 2004). KI is the process of classifying, verifying and storing information and knowledge from various sources (like other users, experts and the semantic web) in a data store like a data mart, semantic knowledge base or digital library. In other words, $\mathrm{KI}$ activities refer to services the portal provides to facilitate the exchange of relevant information to groups in the portal with the same interests. The knowledge and information becomes available for future retrieval to help users or CoPs to solve their problems (Buitendag \& van der Walt 2007).

Figure 3 shows the KI process, as part of the knowledge factory, in the LL framework. It emphasises that organisations receive continuous feedback, verify information and knowledge throughout the KI phases by using knowledge workers. As organisations complete adaptations and new classifications of current knowledge objects, they also keep the various knowledge factory data stores up to date.

One additional solution that organisations could use in conjunction with the standard KI practices is using tools and services. They allow users to combine lexical, structural and knowledge-based techniques to exploit or generate web documents (Martin \& Eklund 2002:18-25). Organisations take advantage of the most popular Internet services. They include emails and the Web itself. They use the Web for distributing uniform information. Knowledge flow relies on populating knowledge elements on the Web. Users can access all types of knowledge, information and news archives over the Internet (Dieng 2002).

Other possible techniques and technologies for discovering knowledge, which use the various research activities (see Figure 1), include:

- data and text mining

- question and answer services

- semantic search techniques

- memorandums

- sharing knowledge via social web spaces like wikis and blogs.

The researchers argue that organisations should remember that several knowledge servers and services, in the form of web services, might cause problems in retrieving available knowledge if they have not arranged and managed the information and knowledge they have stored properly. Furthermore, using sophisticated IT does not always guarantee successful KM.

The role of knowledge is to enable users to choose rational actions so that they become vital components of competitiveness. Organisations should ensure that they receive important knowledge that many others can use and that these contributions improve their processes or outputs (Guo 2006). Organisations can use valuable knowledge to create differential advantage and it can affect their ability to stay ahead of their competitors. Stewart (1997:69) describes the data-to-wisdom hierarchy as, 'one man's knowledge is another man's data'.

In a LL, critical operational and strategic managers are often more concerned with generating reports because they support good decision-making. Therefore, the strategies of managers will determine what the IT system should be capable of and user input will define the system further according to their needs. Hijazi and Kelly (2003) make it clear that the IT infrastructure is essential to support the implementation of knowledge creation.

It is easy to find information with information visualisation software. It produces graphs that assist with identifying complex patterns and relationships in large databases (Zhu \& Chert 2005:139-177). The visualisations may be one-, two- or three-dimensional. One can view related concepts together and colour becomes extremely meaningful. Börner, Chen and Boyack (2003:179-255) define this software as a way of analysing and transforming abstract data (document collections, descriptive words or phrases, journals, author citations or websites) into graphical maps. Reduced search time and discovering developments that might have passed by unnoticed are a huge advantage. 


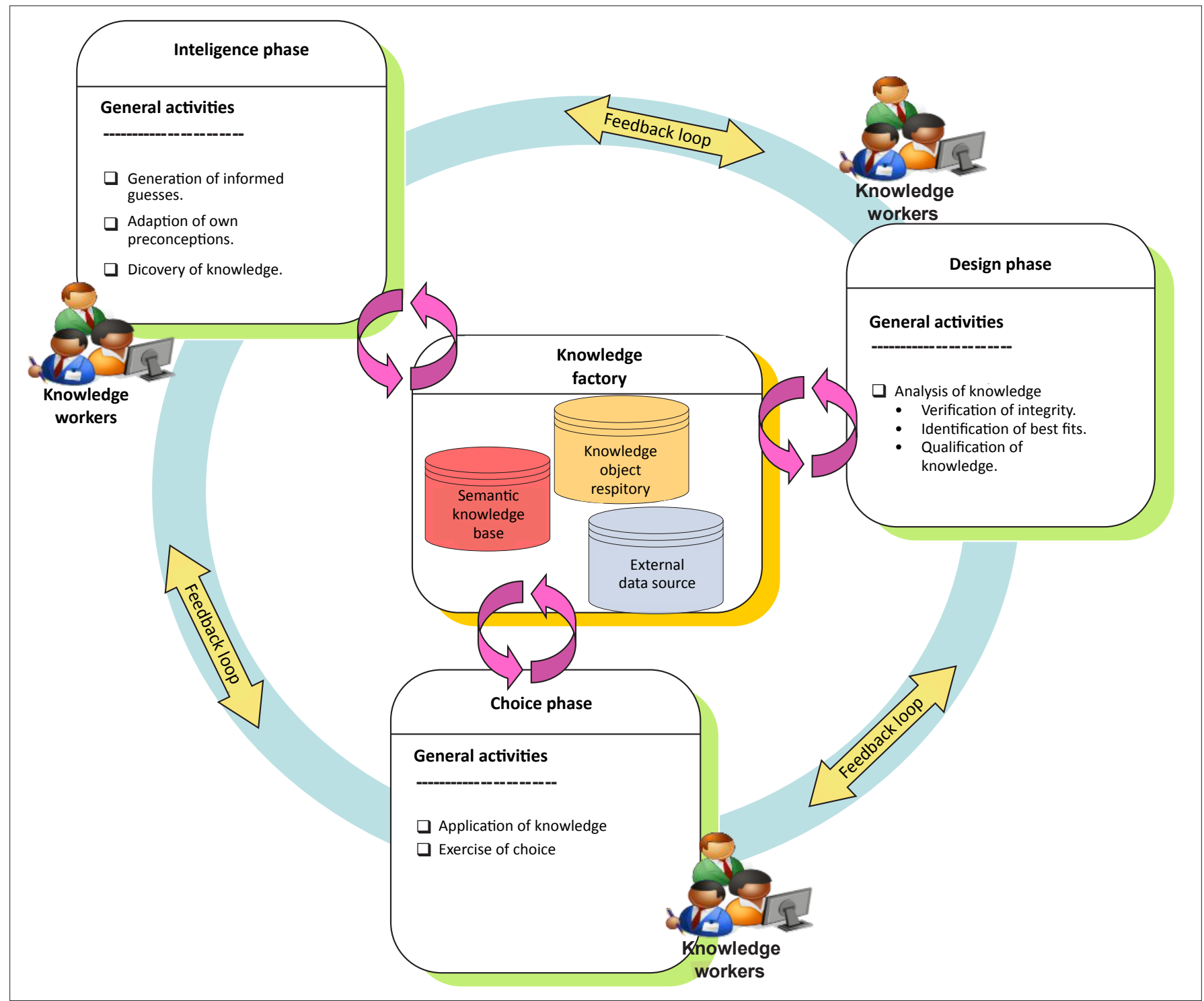

FIGURE 3: Knowledge interchange.

\section{Guidelines for good knowledge management practices}

According to David Skyrme Associates (2008), KM manages its related processes of creating, organising, disseminating and usage to meet the objectives of businesses. There are many KM practices and processes that organisations can apply in a LL environment. The table below, from David Skyrme Associates (2008), highlights some of these practices. They include general KM practices, creating and discovering knowledge, sharing knowledge and learning as well as organising and managing knowledge.

Applying current available technologies and services, like standard data and text mining tools, as well as social media technologies, could support many of the highlighted processes. Skyrme Associates (2008) highlighted them in Table 1.

Another good KM practice is to measure activities that focus on the specific KM practices that organisations apply in their projects or processes to determine their effects. When organisations measure activity, they look at specific things to determine how often users access, contribute to, or use the knowledge resources and practices they have established (Mavodza 2010).

According to Gifford (2011), good KM practice integrates technology and people that a KM expert steers. This will ensure that everyone involved understands its value and will engage in the process.

It is important to ensure that people, processes and technologies align with KM goals and that organisations use best practice approaches in their $\mathrm{KM}$ programmes. This will help organisations to benefit from the skills that people acquire (Gilbert, Morse \& Lee 2007). Guidelines for good KM practices include understanding $\mathrm{KM}$, generating, acquiring, capturing, retaining, organising, disseminating and reusing knowledge. It also involves responding to the new knowledge (Mavodza 2010). 
TABLE 1: Some knowledge management practices and processes.

\begin{tabular}{ll}
\hline Creating and dicovering & Creativity techniques \\
& Data mining \\
& Text mining \\
& Environmental scanning \\
& knowledge elicication \\
& Business simulation \\
& Content analysis \\
Sharing and learning & Communities of practice \\
& Learning networks \\
& Sharing best practice \\
& After action reviews \\
& Structured diaolgue \\
& Share fairs \\
& Cross functional teams \\
& Decision diaries \\
& Knowledge centres \\
Expertise profiling \\
Knowledge mapping \\
Information audits or inventory \\
IRM (information or inventory) \\
Measuring intellectual capital \\
\hline
\end{tabular}

\section{Knowledge management, collaboration and the Internet}

When organisations use the Internet as a social tool for KM, circulating information amongst people and groups as well as in organisations will improve - and innovation will flourish. Internet social tools allow people to access, share and reuse knowledge. The Internet offers remarkable possibilities to access information and knowledge.

The Hyper Text Transfer Protocol (HTTP), mark-up technologies like the Hyper Text Mark-up Language (HTML) and Extensible Mark-up Language (XML) are key technologies for exchanging information and knowledge. Resource Description Frameworks (RDFs) are the key technologies for presenting ontologies. XML and RDFs are two web technologies that allow for significant changes to information interchange worldwide. Many technologies, like the semantic web, have still to realise their potential. Intranets, which rely on Internet technologies, facilitate internal communication and information sharing in organisations. Multidimensional collective organisations, like LLs and multinational corporations, can benefit from the Internet and Intranet to gather, manage, distribute and share knowledge, internally as well as externally.

The roles of the Internet and the social media in creating the correct technological platforms for KM have wide recognition. Knowledge by itself has little value unless organisations can acquire, identify, apply, manipulate and store it for later use (Han \& Anantatmula 2006). Technology can speed up strategic decisions by making knowledge available through databases, Intranets, virtual video conferencing, knowledge repositories and collaborative tools for sharing knowledge (Fotache 2000).

Correct technological platforms ensure that organisations capture, archive and group knowledge correctly. KM allows organisations to integrate and consolidate Intranet platforms. Organisations can benefit from KM by creating and maintaining relevant knowledge repositories, improving access to knowledge, improving the knowledge environment and valuing knowledge.

The researchers constructed Figure 4. It shows the role of the Internet and includes the cloud and Intranets in the LL as part of the knowledge factory. The knowledge factory allows for a general memory management cycle. The cycle and process conform to the practice that Davidson (2002) described.

Organisations must make human knowledge sources like experts, normal end users and single workers from within the LL environment - explicit and available in their memories. Knowledge bases, also called corporate memory bases, store and manage the knowledge. These memory bases contain KORs, which refer to artefacts of knowledge that organisations can apply in LL domains and the semantic knowledge bases that include semantic references to external and internal data sources.

Knowledge objects or artefacts that organisations have referenced and catalogued in the KOR and used, as part of previous knowledge and information enquiries and searches, are available for subsequent searches. Therefore, subsequent searches could become faster because organisations can link previous knowledge to current needs.

External knowledge watchers and workers use external web sources and apply semantic tagging processes that use standard ontologies like the Dublin Core (DC) ontology (dublincore.org 2012) for metadata descriptions. Internal and external expert groups and developers develop, organise and maintain corporate memories. Experts validate knowledge elements before inserting them in the semantic knowledge base or knowledge object repository.

Normal users, which include knowledge seekers, must have easy access to the various memory elements and knowledge objects and they must be able to reuse these elements and objects in order to meet their knowledge requirements. Organisations supervise and manage their LL memory environments or knowledge bases in collaborative processes to ensure that they continually verify the various knowledge stores.

\section{Collaboration software on the Internet}

The rise of the Internet has helped to propel collaboration. Microsoft's SharePoint software (a new generation of Internet-inspired collaboration software) provides alerts, discussion boards, document libraries, categorisation, shared workspaces and the ability to pull in and display information from data sources outside of SharePoint itself, including the Internet (Wilson 2010), amongst others.

The social media improve organisations' KM by promoting ease of use, practical results and emotional gratification 


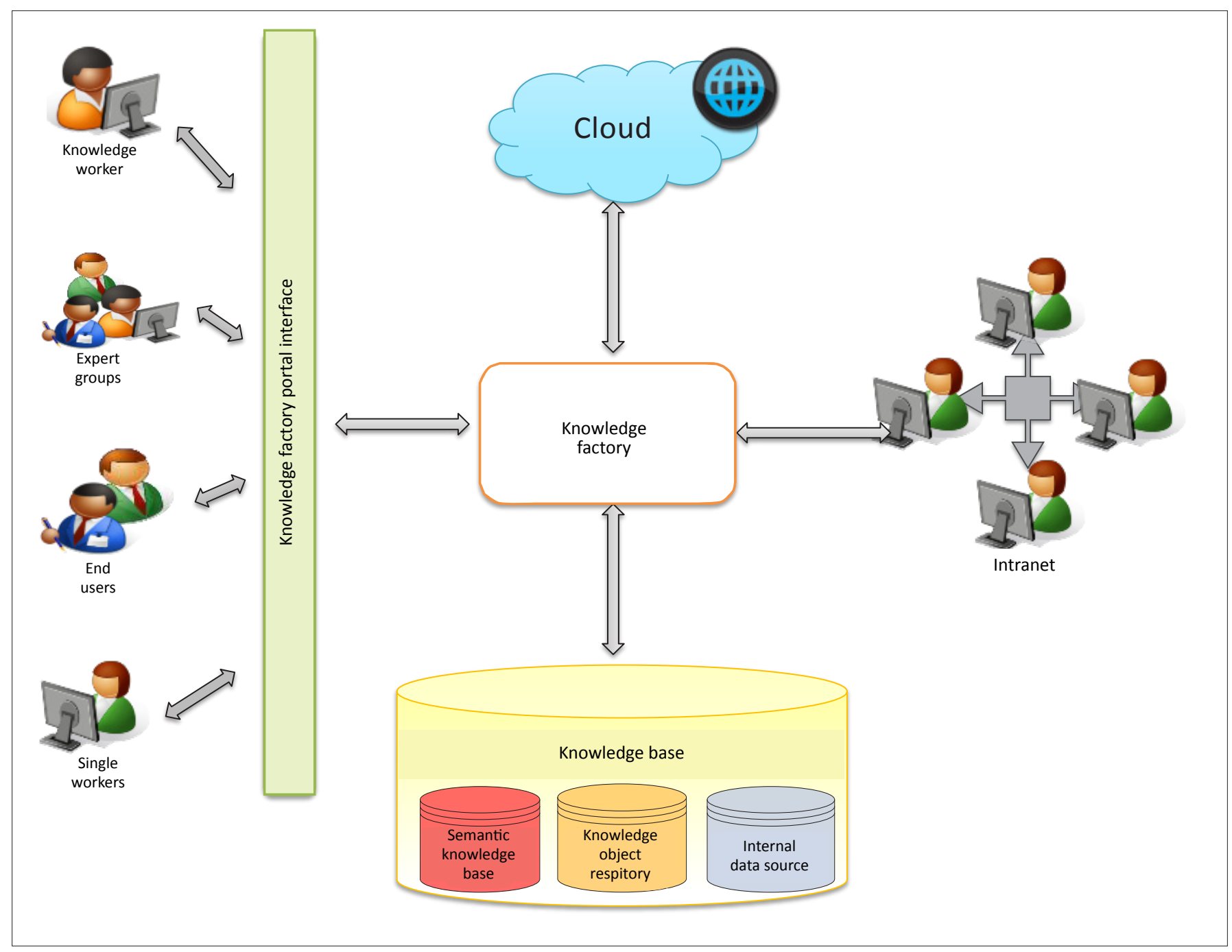

FIGURE 4: Position of the Internet and Intranet as knowledge sources in a Living Lab.

through collaboration systems. The social media make it easy for people to connect with other people, who have posted specific items, with a single click. The social media could improve organisations' collaborative performance without reengineering their current $\mathrm{KM}$ systems. For example, organisations can preserve how they store and structure information as well as integrations like workflows. Therefore, they can reduce migration costs.

The social media allow organisations to get connected and $\mathrm{KM}$ cannot survive without connecting to groups with the same areas of interest. Being connected is all about people, knowledge and opportunities. Srisawas and Rotchanakitumnuai (2011) emphasise that the quality of content on social network sites has major effects on sharing business knowledge and the subsequent value of customer relationships. However, the question of whether KM and collaboration have increased in proportion to the volume of information available, and whether this information would be useful if more people could get their hands on it, remains (Wilson 2010).

White's list of world populations (2010), which includes social media platforms according to country ratings, makes for interesting reading. White lists Facebook as the third largest 'country' on the world map (it accounts for more than $7 \%$ of the world's population), beating the USA. White lists MySpace, Twitter and Orkut (as well as mobile platforms like Facebook mobile) all in the top 20. David Tice (2011), vice president and group accounts director of Knowledge Networks, said that the success of the social media lies in them being people-centred.

\section{The Living Lab Knowledge Management framework}

Figure 5 shows the LL framework the researchers developed from the exposition they have given. It incorporates the various technologies the researchers have described. Knowledge support is an activity rendered as part of the knowledge factory. Figure 5 shows that various users and tools, like Web 2.0, are all possible sources of data and knowledge. The knowledge factory consists of three key systems. They comprise various services its intended user community needs to meet its knowledge support needs and requirements. The services include a KM system, a learning system and a knowledge support service. The primary objective of a KM system is to ensure the validity of the 


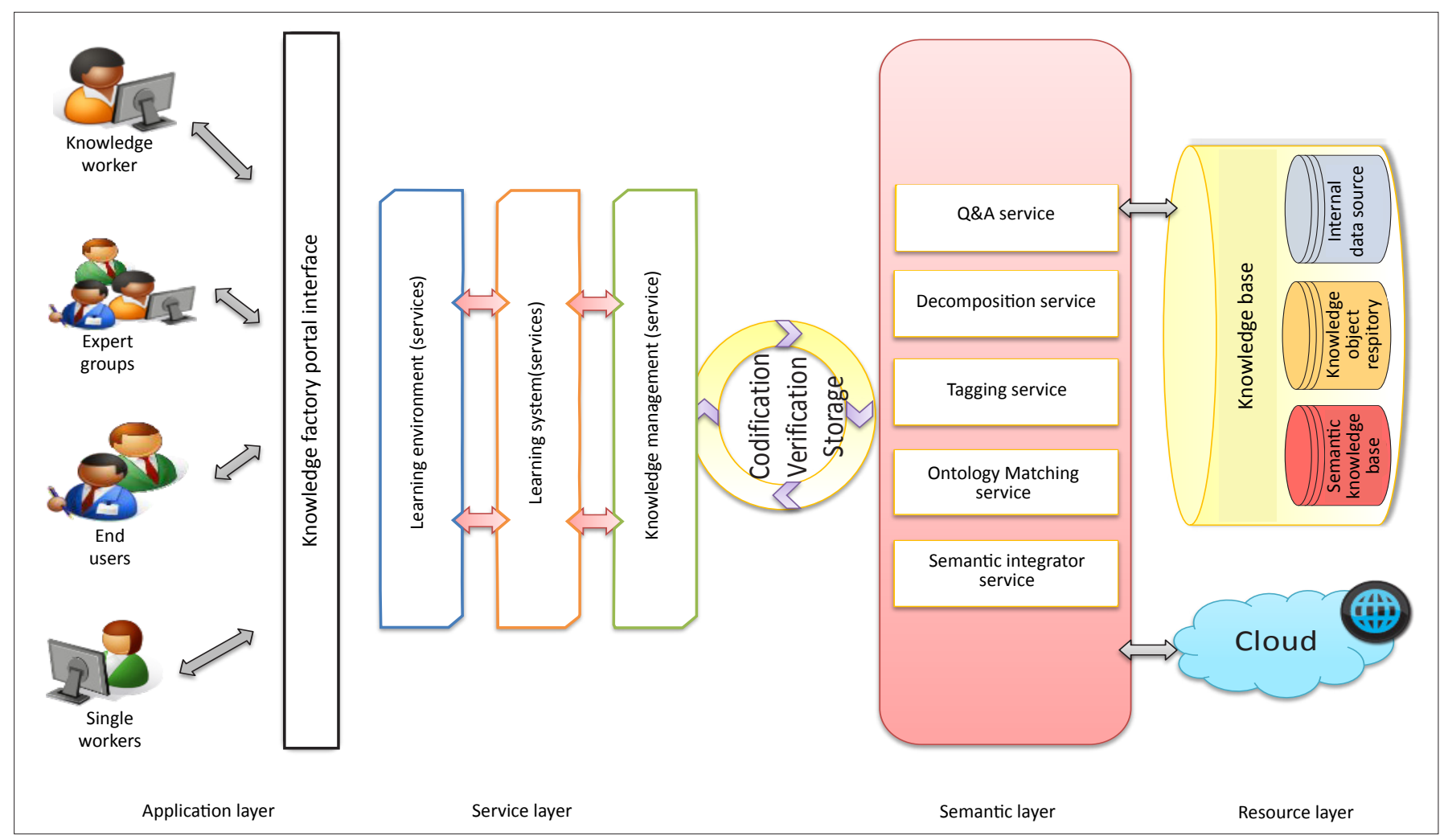

FIGURE 5: The Living Lab Knowledge Management Framework.

knowledge or solutions that users post. It uses the standard knowledge sharing practices that industry has adopted.

A learning system (LS) means implementing the Knowledge Support Portal (KSP). It comprises many sub-portals like a Question and Answer (Q\&A) portlet. The learning system acts as the physical interface for acquiring and sharing knowledge. It also supports and enables collaboration between the various user groups. The knowledge support service orchestrates the process of acquiring information and knowledge and manages a possible reverse auction service for supplying knowledge.

The researchers' proposed framework for KM within a LL environment (see Figure 5) uses a layered approach. It highlights the position of the various knowledge factory systems and shows that KM activities are part of the services layer. The various services enable the processes Table 1 describes. They comply with the guidelines of Mavodza (2010:242,313). The layered approach comprises an application layer, a services layer and a semantic layer.

The application layer provides the interface that allows different users to access the various tools and the LL environment. The services layer contains the various subsystems, as single or embedded tools to allow learning, and $\mathrm{KI}$ in various formats. Some activities that web services could provide include sharing and clustering knowledge, generating services, providing access to smart tools, automatic tracking and tracing knowledge objects, mobile support and expert interlinking. The cloud, as web services, could render many of these services. The semantic layer provides the technical functionality and embedded process logic of the knowledge support and KI activities. The process of classifying the question domain, which is part of the semantic layer, is a stepwise one. It processes and disseminates questions that users post via the Q\&A interface and the KI. The processes of the semantic layer follow.

They dissect and break down a posted question or request into common sentence units, like verbs, adjectives and nouns. The text mining service uses the sentence parts and performs an initial matching activity with earlier questions stored in the questions and answer repository. They apply and match similarities and artificial intelligence (AI) matching methods and return matching result-sets from the Q\&A repository. They then analyse the returned result-set and original question further by using natural language processing tools and services. The ontology wrapping service uses service ontology for a Q\&A web service based on OWL-S.

They write a knowledge object, that simple knowledge ontology describes, to the KOR, the repository stores, amongst others, and the metadata of stored artefacts in an external data warehouse. They also gather additional web sources using semantic processes from the Web itself. This may include links to other WEB 2.0 sites and extracting other potential $\mathrm{KO}$ metadata. The semantic extrapolation process generates tags that it compares to existing metadata by using semantic pattern clustering in the semantic knowledge 
repository. The repository matches existing classes, relations, axioms, functions and instances of earlier searches and results. The KOR contains metadata descriptions of KOs that apply to the current LL domain, whilst the semantic knowledge repository contains repository references and semantic knowledge from external domains.

The web service or semantic integrator incorporates web services with bus architecture. It uses the Web Services Description Language (WSDL) and Web Ontology Language (OWL) for retrieving and discovering possible data sources that are not part of the current Semantic Knowledge Repository (SKR). It applies this process to external web content and to external domain knowledge bases. Various knowledge officers then evaluate the results retrieved from external sources, as part of the knowledge-seeking process, as part of the research process. They tag the subsequent new knowledge or discoveries, describe them semantically and store them as part of the KOR for future use.

\section{Conclusion}

In today's knowledge-driven economy, companies and teams, which include CoPs, must work smarter and not harder. Now that open source technologies are gaining momentum (based on open standards), companies and organisations must, more than ever before, tap into existing technologies to avoid reinventing the wheel. Therefore, the researchers suggest that CoPs incorporate current successful technologies, which are freely available, to create valuable products, services and knowledge systems.

The social media changed the existing KM paradigm completely. Currently, the social media take knowledge and make it highly iterative. In the old world order, organisations usually created and stored knowledge as a point in time. This often meant it was difficult to access it. Now, cooperation, sharing knowledge and interactivity between people in different physical locations has never been as easy. The researchers are convinced that knowledge support services (like a semantic Q\&A service) as parts of the KM framework, will become key deliverables in developing any informationdriven portal that will become part of a LL.

From a South African perspective, these services can play critical roles in limiting and overcoming obstacles like information poverty and knowledge deprivation. The objectives, uses and advantages of knowledge supportservices are not limited to higher education environments. They apply to knowledge- or information-driven environments, like agricultural and medical ones. The researchers believe that semantic-based web service technologies satisfy the requirements, and improve the interoperability, of distributed service component integration.

\section{Acknowledgements}

\section{Competing interests}

The authors declare that they have no financial or personal relationship(s) that may have inappropriately influenced them when they wrote this paper.

\section{Authors' contributions}

L.D. (Tshwane University of Technology) was the research coordinator. She conducted the research interviews, initiated the investigation into the knowledge management practices of higher education institutions and reported on some of the findings.

A.A.K.B. (Tshwane University of Technology) presented the conceptual and design contributions to the design of the layered KM framework, which incorporates semantic technologies and the use and description of the knowledge objects. A.A.K.B. (Tshwane University of Technology) was responsible for the diagrams.

J.S.V. provided conceptual input and initially designed the generic LL framework, which incorporates the various thinking frameworks, the researchers used as part of this study.

L.D. (Tshwane University of Technology) and A.A.K.B. (Tshwane University of Technology) wrote the manuscript.

\section{References}

Anantatmula, V., 2005, 'Outcomes of Knowledge Management Initiatives', International Journal of Knowledge Management 1(2), 50-67. http://dx.doi. org/10.4018/jkm.2005040105

Aronson, D., n.d., Targeting Innovation, Using systems thinking to increase the benefits of innovation efforts. A version of this article appeared in R\&D Innovator (now Innovative Leader), vol. 6(2).

Bartl, M., Jawecki, G. \& Wiegandt, P., 2010, Co-Creation in New Product Development: Conceptual Framework and Application in the Automotive Industry, viewed 21 May 2011, from http://www.radma.Itd.uk/conference2010/papers_abstracts/ Bartl,\%20Jawecki\%20and\%20Wiegandt.pdf

Börner, K., Chen, C. \& Boyack, K.W., 2003, 'Visualizing knowledge domains', in B. Cronin (ed.), Annual review of information science and technology, vol. 37, pp. 179-255, Information today Inc., Medford.

Buitendag, A.A.K. \& Van der Walt, J.S., 2007, A Question and answer knowledgesharing system to support emergent farmers in Southern Africa, viewed 20 May 2011, from http://www.efita.net/apps/accesbase

Buitendag, A.A.K. \& Van der Walt, J.S., 2009, 'Knowledge support in a living lab environment though the utilization of Web 2.0 and Web 3.0 technologies', Proceedings of the 11th Annual Conference On World Wide Web Applications, viewed 16 May 2011, from http://www.zaw3.co.za

Charmaz, K., 2000, 'Grounded Theory: Objectivist and Constructivist Methods', in N. Denzin \& Lincoln, Y. (eds.), The Handbook of Qualitative Research, vol. 2, pp. 509-535, Sage Publications, New York.

David Skyrme Associates, 2008, Resources - KM basics, viewed 20 May 2011, from http://www.skyrme.com/resource/kmbasics.htm

Davidson, A.L., 2002, Grounded Theory - Defined, viewed 09 January 2009, from http://www.essortment.com/all/groundedtheory_rmnf.htm

Dieng, R., 2002, 'Corporate KM through Intranet and Internet', Web Technologies, ERCIM News 41(3), pp. 14-17.

Digital Marketing Agency, 2010, 4THWeb, viewed 05 May 2011, from http://4thweb. com/social-media-2010-numbers

Doyle, A., 2012, Social Media - Social Media Definition, viewed 14 January 2012, from http://jobsearch.about.com/od/networking/g/socialmedia.htm

DublinCore.org., 2012, The Dublin Core Metadata Initiative, viewed 03 February 2012, from http://dublincore.org/

Eskelinen, J., 2010, 'HELSINKI Living Lab (Volume 2) Convergence of Users, Developers', Utilizers and Enablers, viewed 02 February 2011, from http://www.forumvirium. fi/en/project-areas/innovation-communities/helsinki-living-lab

Fotache, D. (ed.), 2002, Groupware -Methods, techniques and technologies for working groups, Polirom Publishing House, Bucharest.

Gifford, A., 2011, 'Member of Melbourne KMLF', What constitutes good KM practice?, viewed 20 May 2011, from http://www.meetup.com/Melbourne-MLF/ members/13875699

Gilbert, P., Morse, R. \& Lee, M., 2007, Enhancing IT support with KM. Governance and Service Management, CA Technologies, New York.

Groff, T.R. \& Jones, T.P., 2003, Introduction to KM in Business, Butterworth-Heinemann, Philadelphia. 
Guo, Z. \& Sheffield, J., 2006, 'Habermasian Inquiring System: Towards a Genera Framework for Knowledge Management Research', proceedings of the 39th Annual Hawail Internation Hawail International Conference on System Sciences, Hyatt regency Kauai, Poipu, http://csdl2.computer.org/comp/proceedings/hicss/2006/2507/07/250770162c.pdf

Hall, D.J. \& Paradice, D., 2004, Philosophical foundations for a learning-oriented knowledge management system for decision support, viewed 28 February 2009 from http://www.sciencedirect.com

Han, B. \& Anantatmula, V., 2006, 'KM in IT organization for employee's perspective', HICSS proceedings of the 39th Annual Hawaii International Conference on System Sciences - Hyatt regency Kauai, Poipu, Hawaii, January 04-07, 2006, vol. 07, IEEE Sciences - Hyatt regency Kauai, Poipu,
Computer Society Washington, DC.

Herselman, M.E., Marais, M.A. \& Pitse-Boshomane, M.M., 2010, 'Applying living lab methodology to enhance skills in innovation', Proceedings of the eSkills Summit methodology to enhance skills in innovat
2010, Cape Town, July 26-28 July, p. 7

Herselman, M. \& Cunningham, P., 2011, Supporting the Evolution of Sustainable Living Labs and Living Labs Networks in Africa, vol. 1(8)a, IIMC International Living Labs and Living Labs Networks in Africa, vol.
Information Management Corporation Ltd, Dublin.

Hijazi, S. \& Kelly, L., 2003, 'Knowledge creation in Higher Education Institutions: a conceptual model', proceedings of the 2003 ASCUE Conference, Myrtle Beach, South Carolina, June 08-12, 2003, viewed 02 April 2011, from www.ascue.org

Jones, D.M. \& Burger, A., 2009, 'Generic materials property data storage and retrieval for the semiconducting materials knowledge base' $\operatorname{Prc}$ 7449 74491R-10, viewed 20 May 2011, from http://144.206.159.178/FT/ CONF/16436607/16436642.pdf

Kern, R., 2010, '5 Social Media Tools for College Students', US News and World Report: Knowledge Sharing Network: Gradeguru.com, viewed 13 May 2011, from http:// www.usnews.com/education/articles/2010/05/12/5-social-media-tools-forcollege-students

Leask, M., 2009, Web 2.0 and knowledge management for local government in England - A model for the public sector, Brunel University London, viewed 01 May 2011, from http://bura.brunel.ac.uk/handle/2438/3559

Lietsala, K., 2008, 'How I became a commidity', Interaktiivinen Tekniikka Koulutuksessa conference proceedings 2008, Aulanko, Hämeenlinna, April 16-18, 2008, viewed 13 August 2011 from http://citeseerx.ist.psu.edu/showciting?cid=10027364

Lepik, A. \& Varblane, U., 2010, 'How to speak the same language with European Innovation-policy in terms of living labs?' Discussions on Estonian economic policy Summaries, pp. 215-232, viewed 02 February 2010, from http://www.mattimar. ee/publikatsioonid/majanduspoliitika/2010/2010.pdf\#page=215

Malhotra, Y., 2000, 'Knowledge Management for E-Business Performance: Advancin Information Strategy to Internet Time', Information Strategy: The Executive's Journal 16(4), 5-16.

Martin, P. \& Eklund, P.W., 2002, 'Knowledge retrieval and the World Wide Web', IEEE Intelligent Systems 15(3), 18-25. http://dx.doi.org/10.1109/5254.846281

Mavodza, J., 2010, 'KM practices and the role of an academic library in a changin information environment', D.Litt et Phil. thesis, Dept. Information Science, University of South Africa, South Africa.

Melakoski, C., 2007, 'Crave, but scared', The Finnish content production sector views on participation in the economy, and social media, Tampere University of Applied Sciences publication, Tampere.

Merrill, M.D., 2000, Knowledge Objects, viewed 05 June 2011, from http:// mdavidmerrill.com/Papers/KnowledgeObjects.PDF

Mukhlason, A.L., Mahmood, A.K., Arshad, N.I. \& Abidin, A.I.Z., 2009, 'SWA-KMDLS An enhanced e-Learning Management System using semantic web and KM technology', Innovations in Information Technology (IIT), pp. 335-339.

Muller, M., 2010, 'Grounded Theory Methods', Human-Computer Interaction Consortium, Winter Park, Colorado, February 24-28, 2010, viewed 15 September muller
Nabil, S., 2010, Cloud computing for education: A new dawn? International Journa of Information Management 30(2), 109-116. http://dx.doi.org/10.1016/j. ijinfomgt.2009.09.004

Newman, B. \& Conrad, K.W., 1999, A framework for characterizing KM methods, Course notes distributed in the unit, EMGT 298.T1, Practices and Technologies in support of The Introduction to Knowledge Management, George Washington in support of The Introdud
University, Washington.

Otala, L., 2008, Human capital management a competitive advantage, WSOY, viewed 07 May 2011, from http://lib.tkk.fi/Dipl/2008/urn012879.pdf

Pallot, M., 2006, Living Labs, viewed 10 July 2009, from www.ami-communities.eu

Qualman, E., 2010, Socialnomics, World of mouth, viewed 03 May 2011, from http:// www.socialnomics.net/2010/04/13/over-50-of-the-worlds-population-is-under30-social-media-on-the-rise

Reichental, Y., Gamliela, T. \& Ayalb, N., 2007, 'Intergenerational Educational Encounters: Part 1', A model of knowledge 33(1), 1-22.

Roux, L., Buitendag, A.A.K. \& Van der Walt, J.S., 2008, 'Investigating Web 2.0 as a platform for a collaborative Living Lab environment', conference proceedings of the 10th Annual Conference on World Wide Web applications, Cape Town, South Africa, September 03-05, 2008, viewed 19 May 2011, from http://www.zaw3. co.za

Srisawas, S. \& Rotchanakitumnuai S., 2011, 'Social Network Management Enhances Customer Relationship', World Academy of Science, Engineering and Technology 77, viewed 21 May 2011, from http://www.waset.org/journals/waset/v77/v7771, view

Stewart, T.A., 1997, Intellectual capital: the new wealth of organizations, Nicholas Brealey, London.

Systems-Thinking.org., 2011, Systems Thinking: An Operational Perspective of the Universe, viewed 21 May 2011, from http://www.systems-thinking.org/systhink/ Universe, viewed
systhink.htm

Tice, D., 2011, 'Report: OTT Video Viewing Up by One Third in 2011', in Telecompetitor, viewed n.d., from http://www.telecompetitor.com/report-ott-video-viewing-upviewed n.d., from http://

Thompson, A.A., Strickland, A.J. \& Gamble, J.E., 2007, Crafting and Executing Strategy, 15th edn., McGraw- Hill, New York.

Van der Walt, J.S., Buitendag, A.K.K., Zaaiman, J.J. \& Van Vuuren J.J., 2009, 'Community living lab as a collaborative innovation environment' Issues in Informing Science and Information Technology 6, 421-436.

Van der Walt, J.S. \& Thompson, W.J. , 2009, 'Virtual Living Lab. Quality Assurance of meat e-markets for Emergent Farmers in South Africa', Proceedings of the 11th annual conference On world wide web applications, Port Elizabeth, South Africa, annual conference On world wide web applications, Port Elizabeth, South Africa, September, 2-4, 2009, viewed 21 May
ZA-WWW/2009/paper/view/132/12

Wahlroos, J.K., 2010, 'Social media as a form of organizational knowledge sharing. A case study on employee participation at Wärtsilä', MA thesis, Dept. Social Studies, University of Helsinki, Finland

White, D.S., 2010, Global population and Social Media, viewed 17 May 2011, from $\mathrm{http}: / /$ dstevenwhite.com/2010/09/11/global-population-and-social-media-2010/

Wikipedia, 2008, Performance Management, viewed 12 April 2011, from http:// en.wikipedia.org/wiki/Performance-management

Wilson, D.J., 2010, System and method for user driven interactive application integration, International Business Machines Corporation, Armonk, New York.

Zhao, C., Gütl, C. \& Chang, E., 2008, 'How modern technology in KM can support Higher Educational Institutions in modern learning settings', in conference proceedings of the 11th International Conference on Interactive Computer Aided proceedings of the 11th International Conference on In
Learning, Villach, Austria, September 24-26, 2008, n.p.

Zhu, B. \& Chert, H., 2005, 'Information visualization', in B. Cronin (ed.), Annual review of Information science and technology, vol. 39, pp.139-177. 